\title{
Los edificios de paneles más altos de España
}

\section{The highest buildings made of precast load panels in Spain}

\author{
A. del Águila* ${ }^{*}$ I. Gómez $z^{* *}$, M. Borsetti* ${ }^{* *}$ S. Hernando**, C. Fernández ${ }^{* * *}$
}

\section{RESUMEN}

Este artículo describe el proceso constructivo de un conjunto de 484 viviendas realizadas con paneles prefabricados portantes de hormigón. Dicho conjunto edificatorio, de 20 plantas de altura, se compone de diversos bloques que integran además, locales comerciales, oficinas, trasteros, 4 plantas de garaje e instalaciones comunes. El principal interés de este edificio consiste en haber alcanzado veinte plantas sobre rasante y 4 más de sótano con el sistema constructivo de paneles prefabricados de hormigón INDAGSA; el cual dispone de un Documento de Idoneidad Técnica emitido por el IETcC, con el número DIT 452.

Las obras de INDAGSA son conocidas por ser precisas, ordenadas y limpias; debido a estas características, se pudieron establecer visitas no sólo para doctorandos de la ETSAM, sino para estudiantes de la Cátedra de sistemas industrializados y prefabricados.

A través de la descripción del sistema constructivo, podremos mostrar una perspectiva global de las posibilidades de los sistemas de paneles prefabricados de hormigón y las capacidades evolutivas de éstos.

195-12

Palabras clave: vivienda, industrialización, prefabricación, paneles prefabricados, paneles portantes, hormigón arquitectónico, viviendas en altura.

\section{SUMMARY}

This present article describes the building process of a 484 dwelling complex built with precast RC Load-Bearing wall panels. This building, which reaches 20 storey high, includes too Shops, Offices, 4 garage floors and central services. The main interest of this complex is that it gets to be the highest building made with precast RC load panels in Spain. The building system which has been used is INDAGSA precast system. This is well known due to its approval technical document, which was conceived by the "Eduardo Torroja" Construction Sciences Institute (IETCC) (DIT 452).

INDAGSA works are also known to be accurate, tide up and clean. Due to these conditions, visits to the site were possible not only for the researchers but for the students of "Industrialization \& Prefabrication building systems".

This article gives a good description of the industrialized systems involved in the building, trough this we try to show the capacities of precast RC load panel buildings, its advantages and the possibilities for evolution.

Keywords: residential building, industrialization, precast, precast wall panel, precast RC load bearing wall panel, architectural precast concrete panel high rise dwelling.

\footnotetext{
" Catedrático de Universidad. Departamento de "Construcción y Tecnología Arquitectónicas" de la Escuela T. S. de Arquitectura. Universidad Politécnica de Madrid (España).

"* Arquitectos- Becarios de Investigación del Proyecto INVISO y alumnos de Doctorado del Departamento de "Construcción y Tecnología Arquitectónicas". Universidad Politécnica de Madrid (España).

*** Arquitecta. Las Palmas de Gran Canaria (España) 


\section{INTRODUCCIÓN}

En este artículo se describe, en general, el proceso constructivo de una Promoción de 484 viviendas distribuidas en varios edificios y, en particular, la realización con paneles prefabricados de hormigón, llegando en dos edificios a las 20 plantas, que es la mayor altura que se había logrado es España nunca.

Desde que se entró en su conocimiento causó un vivo interés en la Cátedra de "Industrialización y Prefabricación de la Construcción", en el "Seminario de Doctorado de Industrialización" y en la Cátedra U+E de "Hormigón Arquitectónico", todos ellos de la Escuela T.S. de Arquitectura de Madrid, y en la parte del Equipo del Grupo TISE de la UPM que participa en la investigación de Subproyecto 5 del Proyecto Singular y Estratégico para la "Industrialización de la Vivienda Sostenible" (INVISO).

¿Por qué el interés hacia unas edificaciones realizadas con paneles prefabricados de hormigón, cuando se habían hecho ya tantas, y se están haciendo, con estos sistemas cuya tecnología es bien conocida? ¿Y en una Cátedra que Ileva 40 años siguiendo y explicando, entre otras técnicas innovadoras, la evolución de estas materias?

La respuesta era sencilla: se trata de la primera vez que se iban a hacer en España edificios de 20 alturas con este procedimiento, y la ocasión no se podía perder.

\section{Ficha Técnica}

EQUIPO TÉCNICO Y CRÉDITOS

CLIENTE:

Promotora PRYCONSA

ARQUITECTOS AUTORES DEL PROYECTO DE EJECUCIÓN Y DIRECCIÓN DE OBRA:

D. Roberto Tapia Melgosa

D. Jorge Calvo Tapia

COLABORADORES (DE CONCURSO, DE PROYECTO BÁSICO Y DE EJECUCIÓN, DE DIRECCIÓN DE OBRA, Y VARIOS):

SERTA arquitectos

CONSTRUCTORA GENERAL: PRYCONSA

DEPARTAMENTO DE ESTRUCTURAS:

INDAGSA:

D. Luis Cano Muñoz

D. Santiago Giménez La Rosa

Se les propuso a ambas empresas que, por lo que suponía construir unos edificios de 20 plantas con paneles prefabricados, nos interesaría aprovechar la oportunidad de seguir su evolución constructiva. Así planteamos a su consideración y aceptación realizar un seguimiento de las obras, con la siguiente programación:

$1^{\circ}$.- Por un lado, unas visitas puntuales con los alumnos de "Construcción Industrializa-
Técnico, para completar la docencia con visitas reales en obra, como se hacían habitualmente en esta asignatura.

Se trataba de realizar una actividad docente, dentro del camino que sigue la asignatura de evaluación continuada, con supresión de exámenes, con una estrategia similar a la que se va a seguir en Bolonia.

$2^{\circ}$.- Realizar un estudio de seguimiento, mucho más pormenorizado, dirigido por el Catedrático, con participación de Doctorandos del "Seminario de Industrialización" y parte de los Becarios-Investigadores del Grupo "TISE", que participan en el Proyecto Singular Estratégico "INVISO", para la Industrialización de la vivienda.

Ambas Empresas respondieron afirmativamente dando un ejemplo, a añadir al de otras muchas veces, de colaboración UniversidadEmpresa, con actividades de la Cátedra "INDUSTRIALIZACIÓN Y PREFABRICACIÓN" $y$ con el "SEMINARIO DE DOCTORADO DE INDUSTRIALIZACIÓN"

Fruto de esas actividades, del análisis pormenorizado llevado a cabo de las mismas y del extenso conocimiento de la Cátedra en estos temas, es el trabajo que presentamos aquí.

Como se ha dicho, en él se describe, de una manera general, esta Promoción de 484 viviendas, pero nos adentraremos, principalmente, en la descripción técnica y analítica de la realización, en la que se emplean los paneles prefabricados, casi en todas sus posibilidades: portantes; de arriostramiento; y de división interior. arriostramiento; fachadas de hormigón arquitectónico e, incluso, elementos de división interior.

Se piensa que una construcción tan original, al menos desde el punto de vista estructural, de un sistema industrializado bien consolidado, merece el esfuerzo que hemos hecho y es, además, una forma de agradecimiento a unas empresas que están siempre dispuestas a actividades como éstas de colaboración Universidad-Empresa que les proponemos y a la innovación en un Sector tan necesitado de ella. da", seguidas de la entrega de un Informe

\section{DESCRIPCIÓN DEL EDIFICIO}

\subsection{Emplazamiento}

El edificio está situado en la Urbanización denominada "La Rambla" de Coslada (Madrid), más concretamente en la parcela RP-4 y TP-3 entre la avda. de la Constitución (Fachada Sur) y la Avda. de Fuentemar (Fachada oeste). 


\subsection{Programa del edificio}

- Viviendas con 1 dormitorio resueltas en plantas de pisos.

- Trasteros situados en planta inmediatamente inferior a la baja y a razón de uno por vivienda.

- Garaje aparcamiento en cuatro plantas de sótano.

- Zona de piscina para uso de la comunidad en el espacio libre de la parcela.

- Locales comerciales en planta baja.

- Oficinas en planta primera.

Edificabilidad

Planta baja residencial: 409,00 $\mathrm{m}^{2}$

Comercial: $2.410,00 \mathrm{~m}^{2}$

Terciario: 2.674,00 $\mathrm{m}^{2}$

Plantas de pisos: $28.145,00 \mathrm{~m}^{2}$

\subsection{Descripción de la solución adoptada}

Según la MEMORIA del Proyecto:

Se trata de una edificación que consta de 8 bloques denominados de la $\mathrm{A}$ a la $\mathrm{H}$, dedicándose fundamentalmente a viviendas, oficinas y locales comerciales.

Los edificios A y B constan de 4 plantas sobre rasante más cubierta y 4 plantas de Sótano bajo rasante.

Los edificios C y E constan de 8 plantas sobre rasante más cubierta y 4 plantas de Sótano bajo rasante.

Los edificios $\mathrm{F}$ y $\mathrm{H}$ constan de 19 plantas sobre rasante más cubierta y 4 plantas de

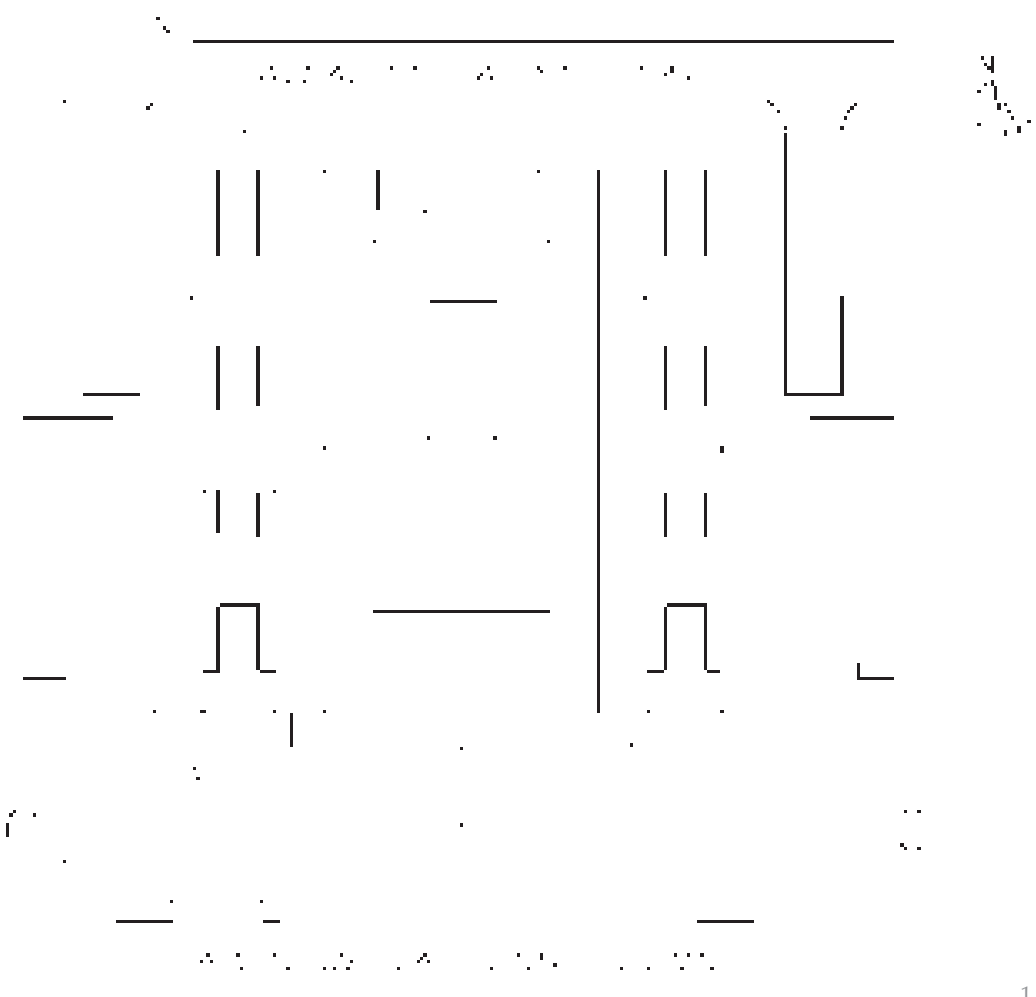

Sótano bajo rasante, son el objeto de la investigación que se va a presentar.

Los edificios D y G están situados en la parte central de la parcela. El edificio D consta de 4 plantas de Sótano bajo rasante. El edificio G consta de 1 planta sobre rasante y de 4 plantas de Sótano bajo rasante.

La contención de tierras de las 4 plantas de Sótano se realiza mediante pantalla perimetral de pilotes.

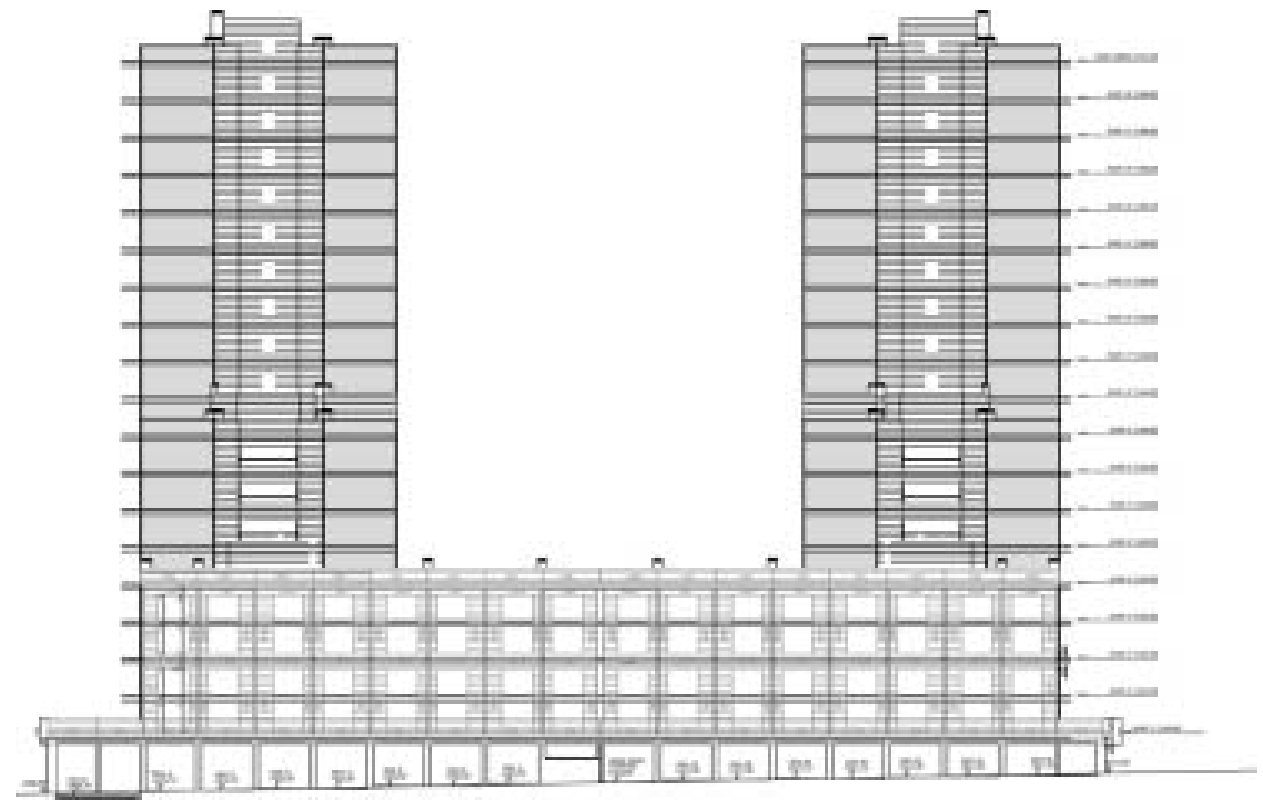


3. El sistema transversal de paneles portantes prefabricados.

4. Pórticos de hormigón armado en planta baja para dejarla diáfana. En él cargan las plantas superiores de paneles.
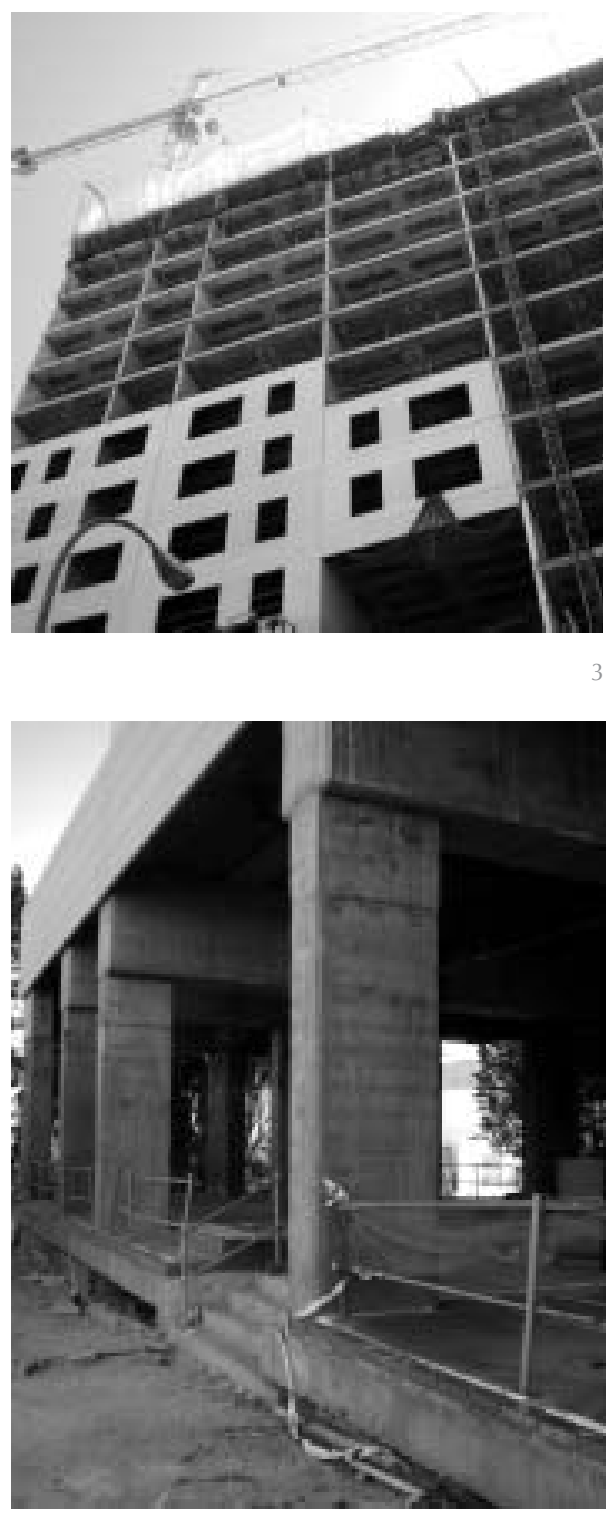

Las plantas están constituidas por forjados unidireccionales in situ. El solar tiene forma rectangular con unas dimensiones aproximadas de $90 \mathrm{~m} \times 90 \mathrm{~m}$.

Los distintos bloques están separados por juntas de dilatación. La Planta Baja de todos los edificios, excepto los edificios D y G, están destinadas a locales comerciales.

En los edificios A y B, las plantas sobre rasante están destinadas a oficinas. En los edificios $\mathrm{C}, \mathrm{E}, \mathrm{F}$ y $\mathrm{H}$, las plantas sobre rasante están destinadas a viviendas, salvo la última planta, Techo 18, que está destinada a instalaciones.

Las plantas de Sótano -4, -3 y -2 están destinadas a garaje. La planta Sótano -1 está destinada a garajes y trasteros. Eventualmente en alguna zona de las plantas de Sótano el uso será de instalaciones.

\section{SISTEMAS CONSTRUCTIVOS Y ESTRUCTURALES EMPLEADOS}

\subsection{El sistema estructural constructivo de la obra}

En esta obra se ha optado por una combinación de sistemas estructurales convencionales, con otros industrializados, cuya mayor innovación se encuentra en el número de plantas, veinte sobre rasante y cuatro sótanos.

Vamos a describir de una forma general los primeros y entraremos en un mayor detalle en los segundos, en los sistemas industrializados.

Los cuatro sótanos y la planta baja porticada se resuelven con construcción tradicional.

A partir de los pórticos de planta baja, se comienza con la construcción mediante paneles hasta la planta veinte.

También la realización de forjado se hace con vigueta y bovedilla cerámica, con unas luces variables, con un máximo de 6,60 m.

En cambio, los núcleos de ascensores, que sirven de arriostramiento del edificio, son de paneles prefabricados de hormigón armado desde el último sótano.

Hagamos una descripción de todo ello, incidiendo en la obra de paneles prefabricados.

\subsection{El sistema INDAGSA}

Es un sistema constructivo basado en paneles portantes de hormigón armado, prefabricados de forma racionalizada, en taller. El sistema está enmarcado dentro del grupo de paneles de hormigón armado previstos para trasdosar.

Estos elementos una vez montados en obra constituyen el cerramiento y/o la estructura del edificio.

El sistema INDAGSA es de junta seca, puesto que las uniones entre los paneles se realizan con anclajes soldados, lo que confiere rigidez instantánea al edificio y proporciona una gran rapidez de montaje y ejecución de obra.

\subsection{Objeto de trabajo}

Nos vamos a referir, principalmente, a este sistema de paneles prefabricados en la construcción de los edificios $\mathrm{F}$ y $\mathrm{H}$, que son los que representan la mayor innovación, pues constan de 20 plantas sobre rasante y 4 plantas de sótano. 
Como se ha dicho en la introducción, el haberlos realizado con paneles prefabricados de hormigón, los convierte en un hito tecnológico de estos sistemas en España.

La estructura principal es, pues, de paneles prefabricados de hormigón armado en su posición de paneles resistentes perpendiculares a fachada, con lo que la dejan libre para la composición arquitectónica al no tener ésta una función estructural. Van apoyados en planta baja en pórticos de hormigón armado hechos in situ, que dan una mayor diafanidad a estas zonas.

También se emplean paneles prefabricados de hormigón, pero esta vez "arquitectónico", en fachadas, pero sin función estructural, aunque son autoportantes y cuya descripción se hace en el apartado 5.

\subsection{Comentarios a la solución estructural y a las hipótesis de cálculo}

El sistema estructural concebido de este modo se corresponde con lo definido en el apartado 1.5.2 ("Asociación de pantallas y entramados") del libro "Proyecto y cálculo de estructuras de hormigón armado para edificios", Tomo 1 de INTEMAC, en que manifiesta su mejor funcionamiento respecto a cargas horizontales que las estructuras formadas por entramados exclusivamente, como se afirma en la memoria.

Si consideramos que los elementos de arriostramiento del edificio están constituidos por los paneles resistentes verticales prefabricados, el libro "Edificio de viviendas prefabricados con elementos de grandes dimensiones" de Bohdan Lewicki (1) es, a pesar de su antigüedad, muy claro, así lo expresa en el apartado 5.3.1, "Esquemas de funcionamiento de los muros de arriostramiento" expresa el modelo a seguir de una forma muy clara (ver figura libro).

Acerca del Profesor polaco Lewicki (1) hay que expresar que supuso en la construcción y el cálculo, que muchos hemos usado y se sigue utilizando, en el diseño de paneles prefabricados de hormigón. Era un asiduo visitante del IETcc en los años sesenta y, sólo se podía llegar a su importante bibliografía a través de la traducción de las traducciones del francés. En 1968, el Prof. Aguirre de Yraola, antiguo Director del IETcc, lo tradujo al español y, ¡todavía!, se sigue vendiendo su libro. Los edificios construidos con este sistema se conciben como estructuras formadas por grandes elementos verticales que se constituyen al agruparse los paneles prefabricados, trabajando como ménsulas flechadas en su plano, como indica Lewicki y corroboran Halász y Tantow (2).

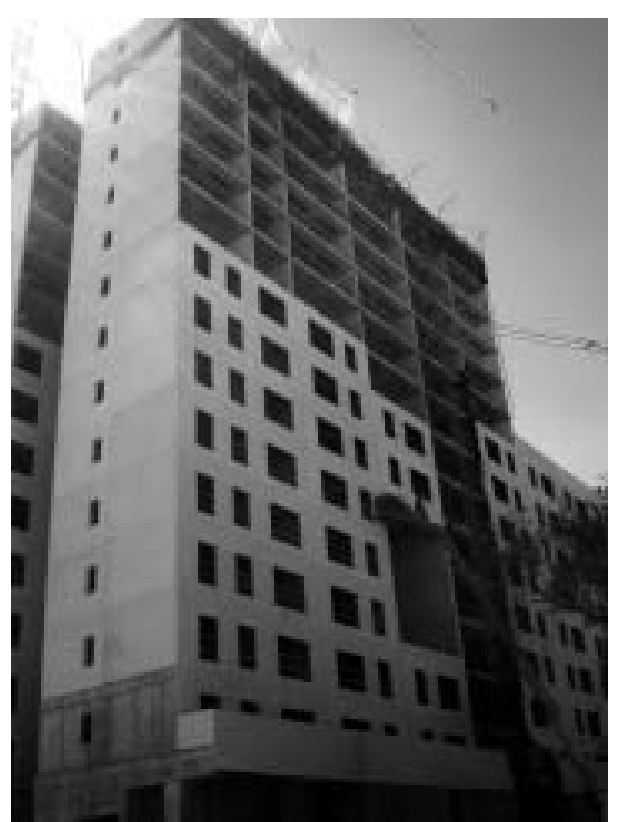

5. Edificio de 20 plantas: montaje de los paneles arquitectónicos de fachada.

6. Esquemas de funcionamiento de los muros según Lewicki.
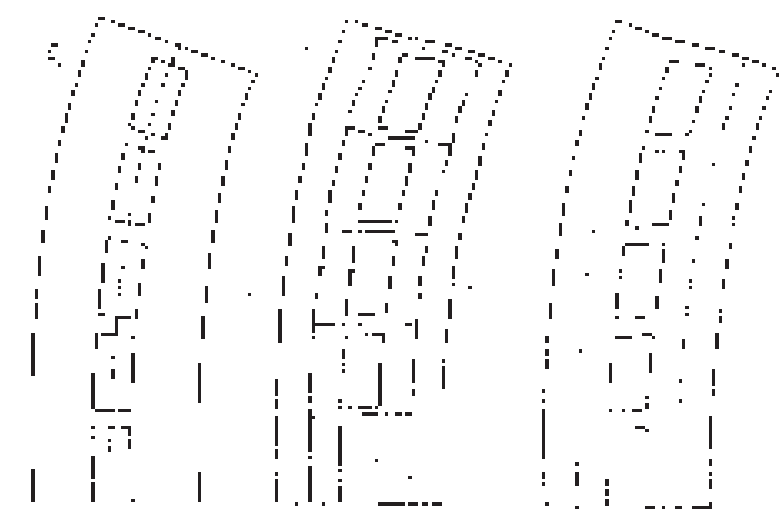

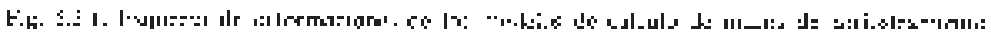

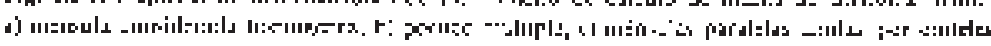
I-rn'

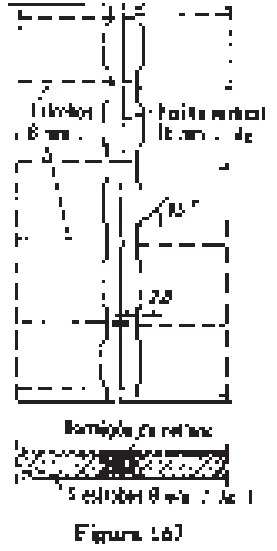

ل

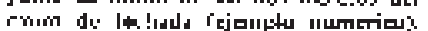

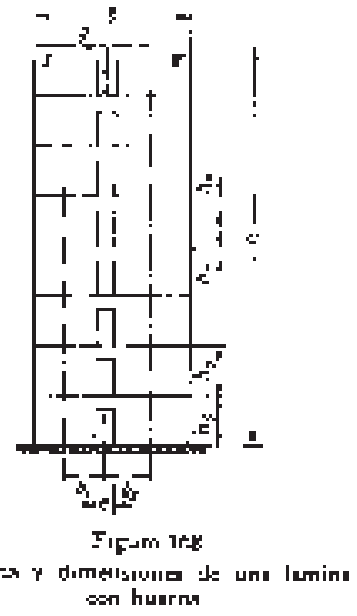

$\Leftrightarrow$ hurrn
La unión entre los elementos prefabricados es articulada, de forma que la rigidez transversal de cada elemento vertical es despreciable. 
7. El cálculo estructural del sistema.
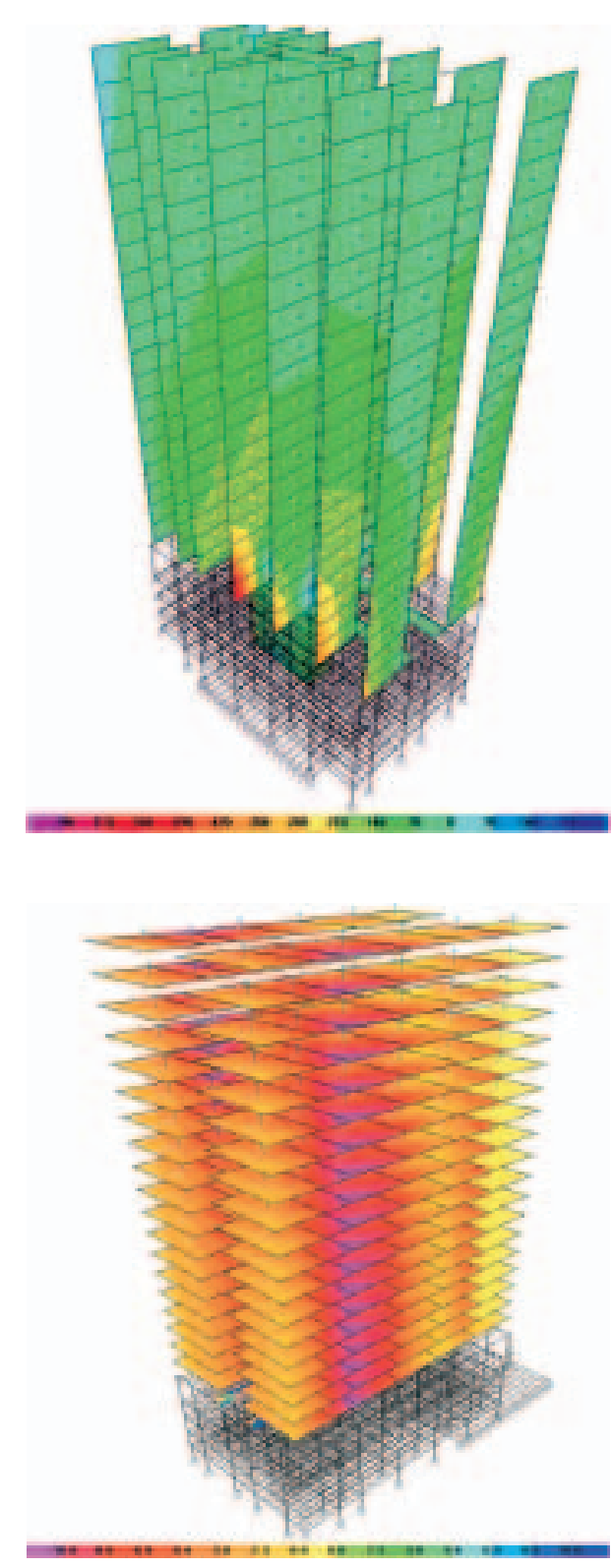

Por supuesto, que para que los edificios tengan la estabilidad suficiente se disponen en las dos direcciones, o a través de núcleos rígidos, por ejemplo, de escaleras y ascensores, como se ha usado en este caso. Como se comprende, esta consideración de rigidez-estabilidad es básica en un edificio de esta altura realizado con paneles.

Además de toda la casuística que exponen las "Directrices comunes de la UEAtc" sobre estos sistemas, también se consideran todos los esfuerzos, que aparecen específicamente en ellos, según los " $A$ ", " $B$ " $y$ " $C$ ", de adherencia al molde, de manipulación y de montaje y de situación definitiva en la obra.

En el cálculo de estabilidad se comprueba la rigidez del edificio en los sentidos longitudinal y transversal, pudiendo, como afirma Indagsa en la Memoria de Cálculo, admitirse que la rigidez del edificio es suficiente cuando se cumple que la flecha máxima ( $\mathrm{max}$ ) en coronación es menor que hb/2000, siendo hb la altura del edificio.

Igualmente, en el proceso de cálculo se comprueban las fechas a flexión, en sentido longitudinal y transversal, con un reparto de cargas entre las distintas ménsulas en sentido OX y OY, proporcionalmente a sus rigideces.

En ese aspecto, el primero que habla del funcionamiento como "ménsulas" es B. Lewicki (1) (ver "5.4. Cálculo de la rigidez" de su obra citada), colaborando posteriormente Von Halász y Tantow (2) ( ver "Cap. 6. "Estética de la construcción con grandes elementos", también de su citado texto").

Si en la distribución en planta del edificio que se está diseñando no existe una cierta simetría en la disposición de las "ménsulas" formadas por el plano de los paneles se produciría un efecto de torsión en el edificio, ante lo cual se suelen distribuir las cargas debidas al momento torsor entre las "ménsulas" en función de su rigidez y de su distancia al centro de torsión del edificio. En el cálculo de estabilidad, la oficina Técnica de INDAGSA ha utilizado programas de carácter general, como son los de CYPE, TREBOL, etc.

Según se indica, acertadamente, en la Memoria de Cálculo facilitada, para que el conjunto de los paneles asociados verticalmente funcionen como ménsulas, hay que comprobar que las juntas verticales entre los mismos sean capaces de resistir los esfuerzos a cizalladura que aparecen en los mismos, como se recoge en los apartados "5.2. Requisitos para la construcción de las juntas" y en el "6.3. La ménsula laminar compuesta de elementos aislados", en el libro citado de Von Halász y Tantow (2).

\subsection{El papel estructural de las placas de anclaje}

Esta transmisión de cargas entre paneles verticales se consigue en estos edificios mediante la unión por soldadura de las placas de anclaje existentes entre paneles contiguos, complementada con el armado del zuncho al nivel de planta.

En el sistema Estiot-Hochflet que incorporan en la citada Memoria como ejemplo, no nos ha parecido un ejemplo bien elegido, sobre todo por su antigüedad (alrededor de 50 años), la tipología de sus paneles, ya que usaban paneles sándwich hormigónpoliestireno (cuya tipología se abandonó en los años setenta) por la tipología de sus 
juntas, que no son "secas", como se han utilizado en "La Rambla", sino "semisecas", con papel importante dado al hormigón vertido in situ y el uso de losas macizas de hormigón armado como forjados en vivienda, que también se desecharon hace más de 30 años.

\subsection{El papel del espesor de los paneles}

Para el dimensionado del espesor de los paneles, Indagsa admite la formación de una articulación en el borde del panel considerado y, por tanto, aceptando que no se transmiten cargas de flexión entre forjado y paneles ni entre paneles.

Todas estas cargas se ven afectadas por distintos tipos de "excentricidades" a considerar debidas a defectos de disposición, o a acciones del viento, sismo y causas térmicas. Con todo ello se llega a la "excentricidad de cálculo", según la monografía del IETcC $n^{\circ} 276$, referida a "Paneles prefabricados de hormigón".

Los anclajes, como se ha indicado al principio de este capítulo, realizan la transmisión de esfuerzos entre paneles.

Aquí se han usado los casquillos metálicos de UPN 80 o L70.7, que llevan incorporadas cuatro patillas rectas $\varnothing 8 \mathrm{~mm}$ de acero B500S y longitud $35 \mathrm{~cm}$, que se colocan en la base de hormigonado.
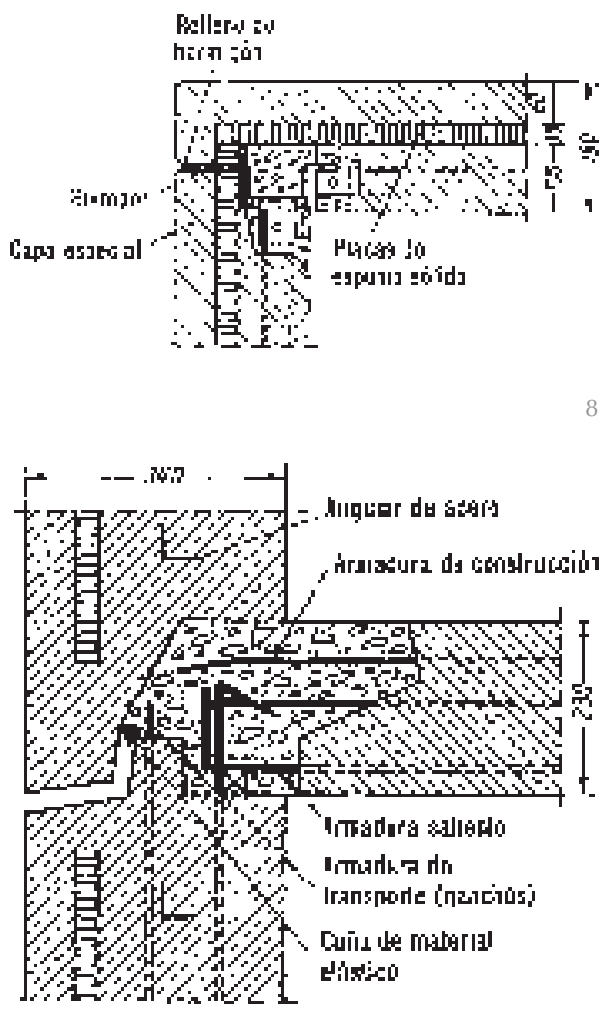

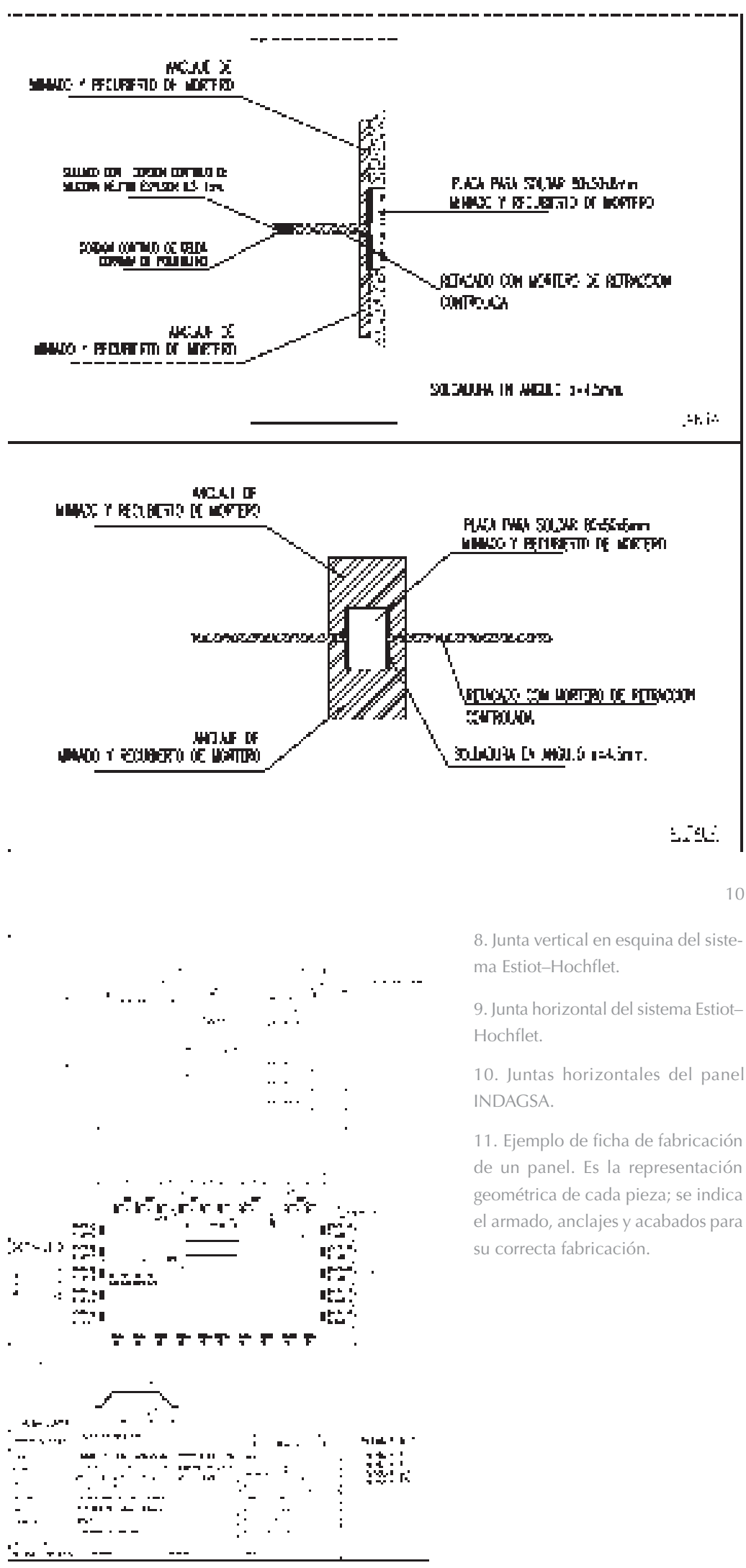

Como indica la "Memoria": "El monolitismo del forjado se garantiza colocándose la armadura necesaria en el zuncho perimetral del forjado; el mecanismo para transmitir los esfuerzos horizontales entre el forjado y el 

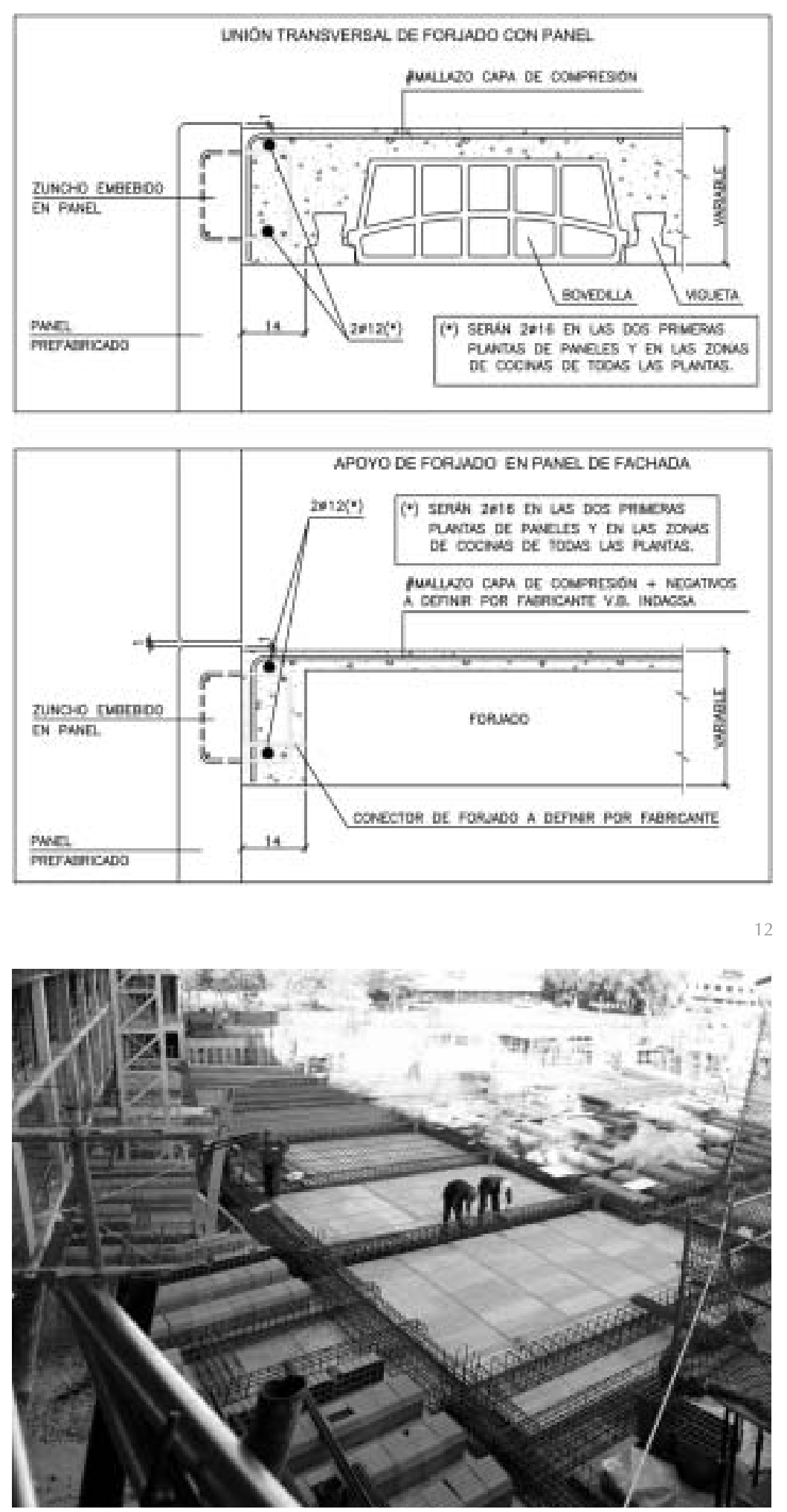

13

panel se basa en el macizado de hormigón que penetra en las Ilamadas "almenas" (huecos en el borde superior de los paneles) y, si fuese necesario, en las "cachavas" (armaduras que se dejan embebidas en los paneles para facilitar la manipulación de éstos).

el forjado.

13. Vista del forjado de tipo tradicional del edificio.
Como ya se ha dicho, se emplean en estos edificios forjados de vigueta y bovedilla, al ser una exigencia de la promoción la instalación de luces en techo, sin usar falsos techos.

\subsection{La cimentación}

El edificio ocupa un solar rectangular de dimensiones aprox. 90x90 m.

Se encuentra aislado como una manzana autónoma: sin excavaciones ni edificaciones adyacentes; no obstante, el proceso constructivo debe respetar la altura de urbanización existente en su alrededor.

Además, es necesario incorporar la mayor superficie posible disponible bajo rasante; En este caso, 4 alturas excavadas fueron suficientes para ubicar el programa de aparcamientos, trasteros e instalaciones comunes.

Debido a las condiciones anteriores y a la facilidad de excavar y perforar el terreno (son principalmente arenas y margas), es fácil entender el método de cimentación empleado: pilotes con camisa recuperada en la totalidad del perímetro con separación entre pilotes de 40-50 cm. Se realiza viga de atado que une en perímetro la totalidad de las cabezas de los pilotes para la transmisión de cargas.

Para el interior del solar, una vez excavado, se emplean zapatas individuales con vigas de atado. Están concebidas para una transmisión de cargas de $70 \mathrm{~N} / \mathrm{cm}^{2}$.

Los núcleos de escaleras, se realizan con paneles prefabricados resistentes de hormigón armado. Desde la cimentación, tras la regularización de la superficie de la losa de cimentación propia de un núcleo rigidizador.

\section{ANÁLISIS DE LA PLANIFICACIÓN DE PUESTA EN OBRA}

Uno de los aspectos más importantes, y quizás el más convincente a la hora de trasladar al constructor las ventajas de los sistemas de prefabricación es la minoración de los tiempos de obra, así como la reducción óptima del equipo material y humano necesario para llevar a cabo las operaciones de levantamiento de la estructura.

Como es lógico, al emplear estructura prefabricada (resistente desde la correcta colocación de ésta y de sus necesarios arriostramientos) no se requieren tiempos de espera hasta que la estructura alcance las resistencias mínimas necesarias para el avance en vertical. Es por esto, al igual que sucede con estructura metálica, por lo que se mejoran sustancialmente los tiempos de obra. 


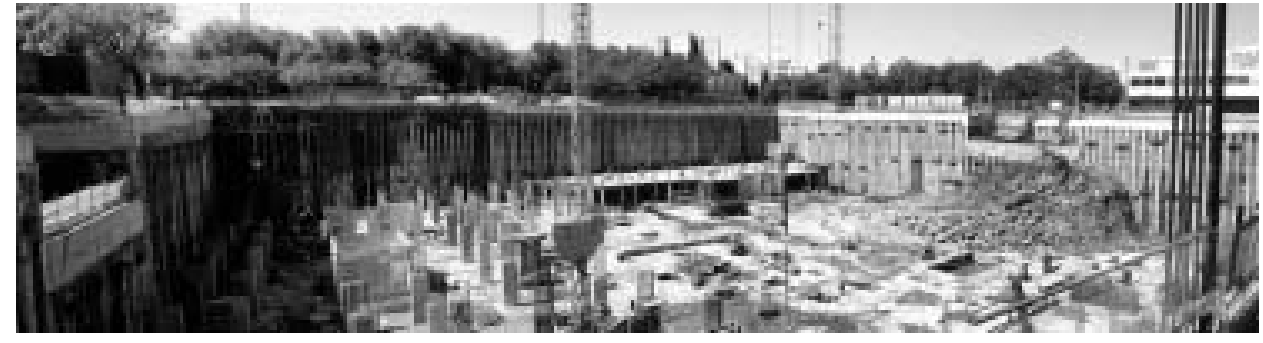

$22 / 05 / 2009$

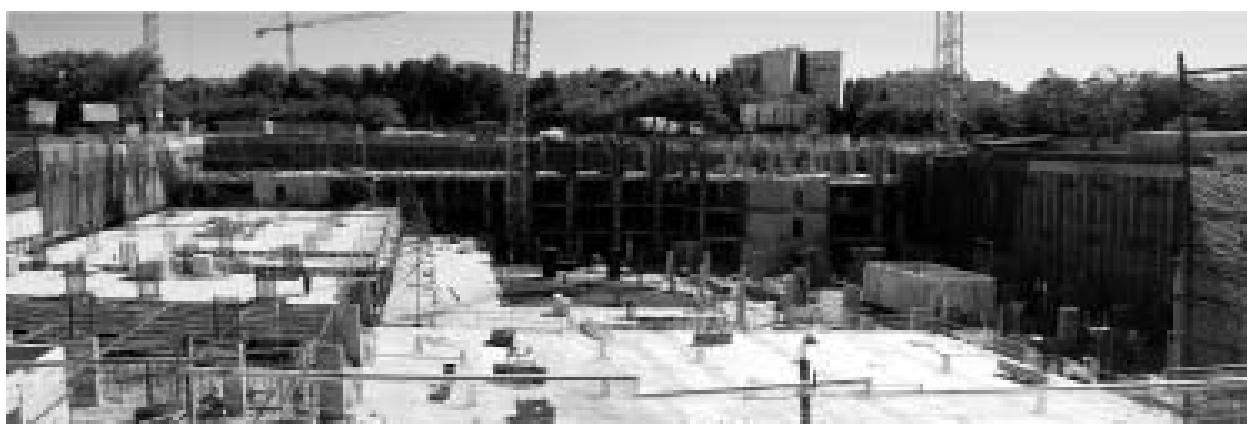

09/07/2009

CLIENTE: PRYCONSA.

PLANIFICACION Montaie.

PANELES POATANTES.

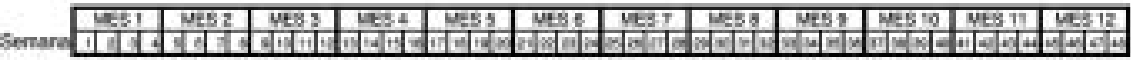
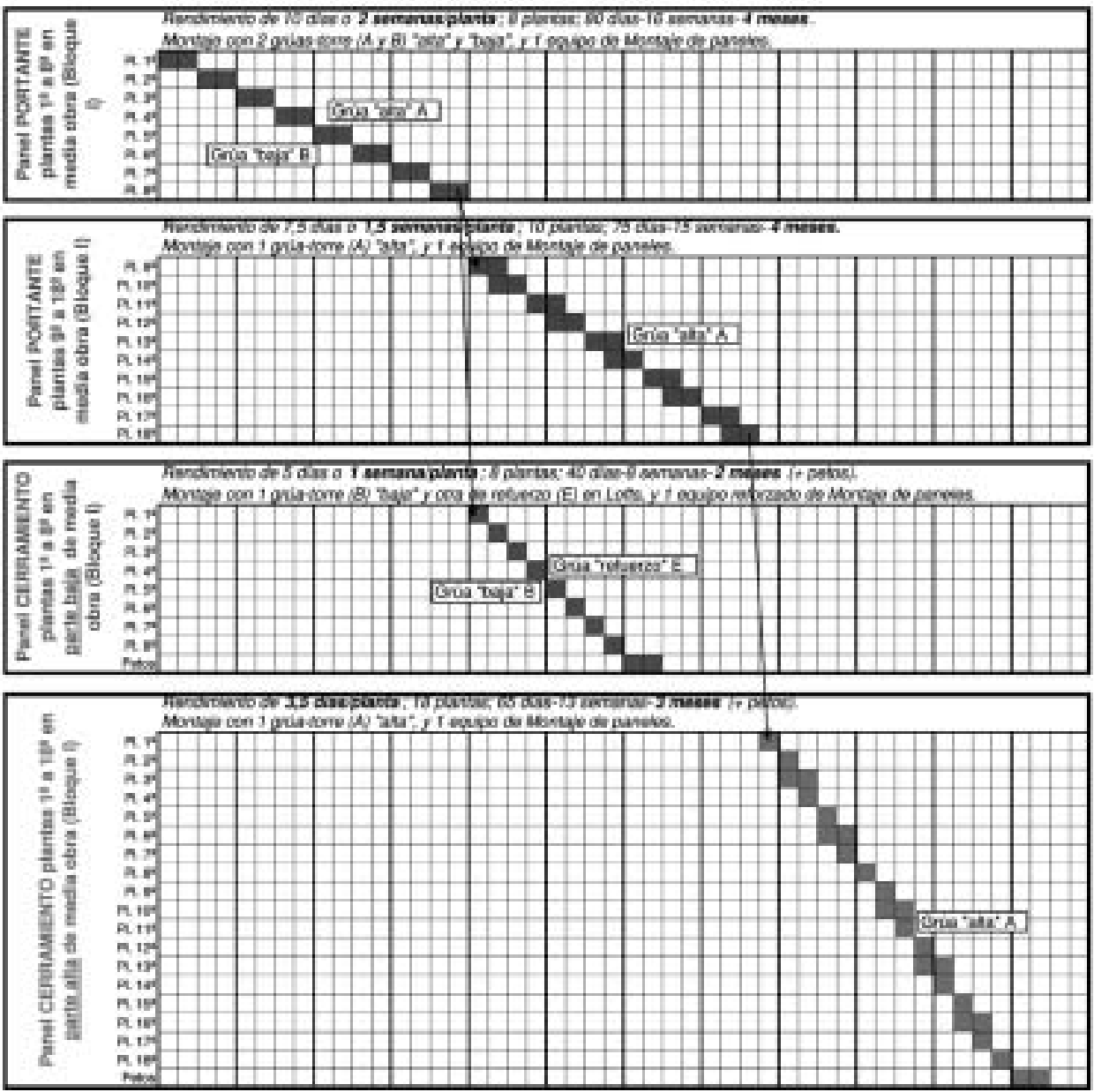

14. Ejecución de la cimentación.

Apréciese el avance obtenido en el plazo desde el 22 de mayo hasta e de julio, mes y medio para lanzar 3 plantas. Buena coordinacion para a racionalización de los encofrados en conjunto con los paneles prefabricados.
Notese también la importancia de coordinar el empleo de los medios auxiliares, con aspectos tan importantes como la interoperabilidad de as hasta 5 grúas, para no tener que sufrir duplicidades que perjudiquen el rendimiento de la inversión. Nótese que además de la reducción de los tiempos de construcción de estructura por planta, estando éstos comprendidos entre 1.5 y 2 semanas/ planta, hay que hacer mención de las numerosas unidades de obra que se están realizando simultáneamente a través de los paneles prefabricerramientos; divisiones; cajas de ascensores; medidas de seguridad ncorporadas. 
Montaje de paneles portantes en núcleos de sótano 4, al mismo tiempo que se va ejecutando la estructura realizada in situ.

Ejecutada la estructura de transición (vigas de cuelgue), se comienza el montaje de paneles portantes en planta primera.

Montaje de paneles portantes en plantas octava y novena. Montaje de paneles de cerramiento en plantas cuarta y quinta.

Montaje de paneles portantes en planta trece. Montaje de paneles de cerramiento en plantas octava y novena.

Finalizado montaje paneles portantes. Montaje de paneles de cerramiento en ultimas plantas. Pendiente de montar zona de montacargas.

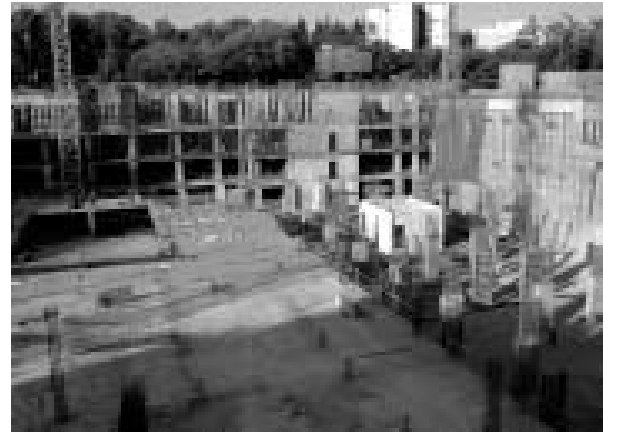

9 de Julio de 2007

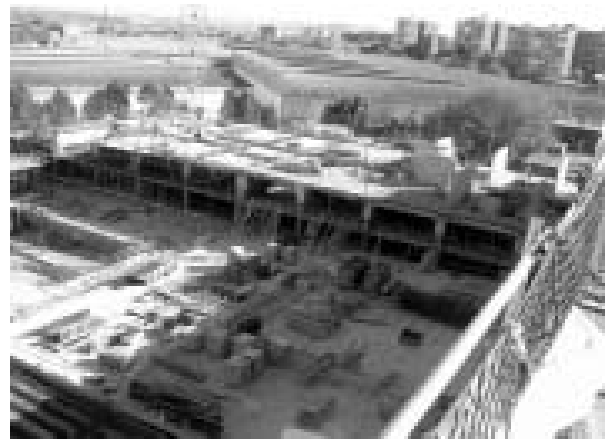

13 de Noviembre de 2007

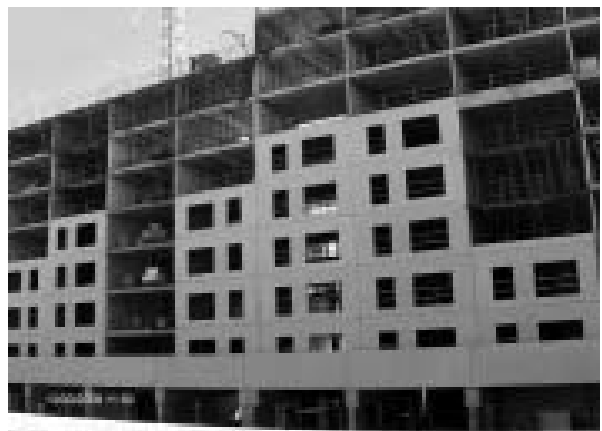

13 de Marzo de 2008

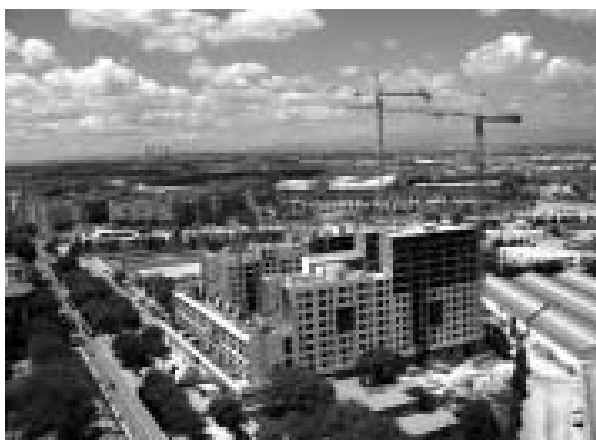

20 de Mayo de 2008

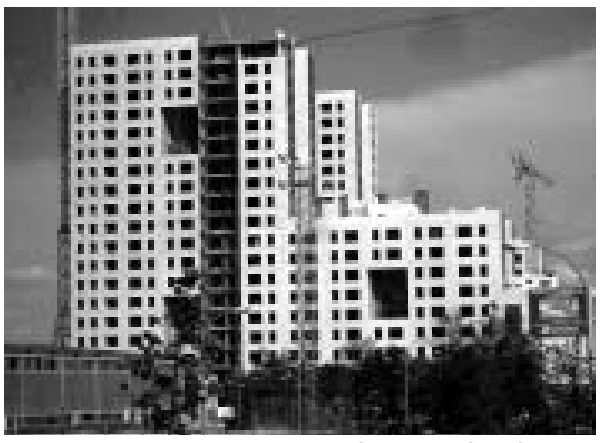

30 de Septiembre de 2008
En el caso concreto de esta obra, la constructora asegura ahorrar hasta en un tercio el tiempo de obra respecto de una estructura convencional.

Completándose, como se aprecia en la planificación que ilustra la figura, el montaje de estructura y cerramiento para las 18 alturas de edificación con paneles prefabricados estructurales y de hormigón arquitectónico en fachadas (autoportantes sin función estructural) en apenas 11 meses y medio.

Además, la construcción a través de elementos prefabricados minimiza de forma sustancial las tan frecuentes desviaciones de tiempo y dinero que se reproducen en la mayoría de las obras de construcción convencional, producto de errores de interpretación de planos, dificultad de montaje y ejecución de "alegres" detalles constructivos, problemas de materiales (resistencias insuficientes de las probetas de hormigón a 7, 14, 28 días), vacíos en el proyecto que se pretenden solucionar a pie de obra (soluciones ad hoc).

Esta reducción en los tiempos de obra y la minimización de los frecuentes errores repercute positivamente en la seguridad de la financiación de la obra, debido tanto a la recuperación de la inversión económica en menor plazo, como a la reducción de los periodos de alquiler de los medios auxiliares empleados.

A pesar del requisito de empleo de mano de obra especializada, esta especialización
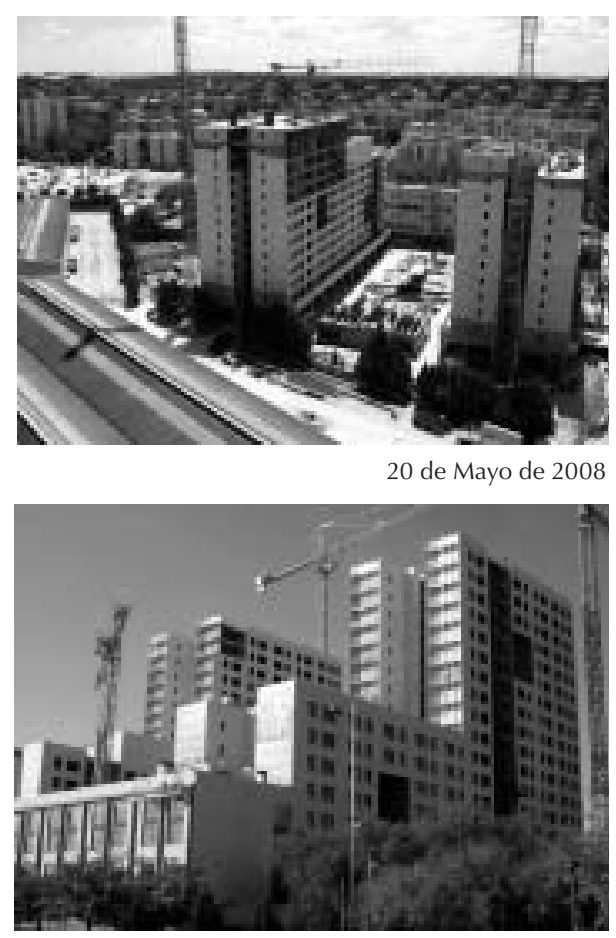

30 de Septiembre de 2008 
puede alcanzarse con relativa facilidad, y a corto plazo, pudiéndose realizar directamente en la propia obra, debido a la sencillez de las operaciones que han de acometer los/as trabajadores/as.

Es de vital importancia reconocer en la planificación de la obra una de las claves para la reducción del riesgo de inversión de capital. Más aún en esta época en que no pocas constructoras se han visto agotadas debido a disponer la mayor parte del capital (propio o procedente de préstamos) inmovilizado en obras aún por terminar, de modo que imposibilita afrontar el pago de los préstamos e intereses.

\section{FACHADAS DE HORMIGÓN ARQUITECTÓNICO}

Las fachadas se realizan con paneles de Hormigón Arquitectónico, que actúa como hoja exterior del cerramiento.

Los paneles tienen un espesor de $8 \mathrm{~cm}$, de hormigón blanco, de cemento tipo BL1 y árido blanco.

El acabado es liso en su totalidad, salvo en la franja entre carpinterías que tiene un acabado grecado que mejora el comportamiento de estos hormigones frente al ensuciamiento ambiental.

Estos paneles no asumen ninguna función estructural en el edificio, ni siquiera de arriostramiento de la estructura, ya que ésta se arriostra en los núcleos de comunicación. Aunque los paneles de fachada, "no estructurales" sí aportan cierta rigidez a la estructura, no se tiene en cuenta esta resistencia en el cálculo estructural, entre otras, debido a que parte de la función estructural que podría solicitarse a este tipo de panel surge con anterioridad a la colocación de los paneles de fachada.

El anclaje de los paneles de fachada se realiza mediante chapas metálicas embebidas en los paneles, que se unen por soldadura a los paneles estructurales también prefabricados de hormigón armado.

También existen unas conexiones que se consideran secundarias de los paneles de fachada al forjado, mediante este tipo de anclajes, cuya función es sólo impedir, en cierta medida, el alabeo de los paneles.

Existen diferentes tipos de paneles en la fachada, que aunque posean los mismos acabados, pueden tener distintas dimensiones o incluso distintos puntos de anclaje que los convierten en paneles distintos en el proceso de fabricación y puesta en obra.

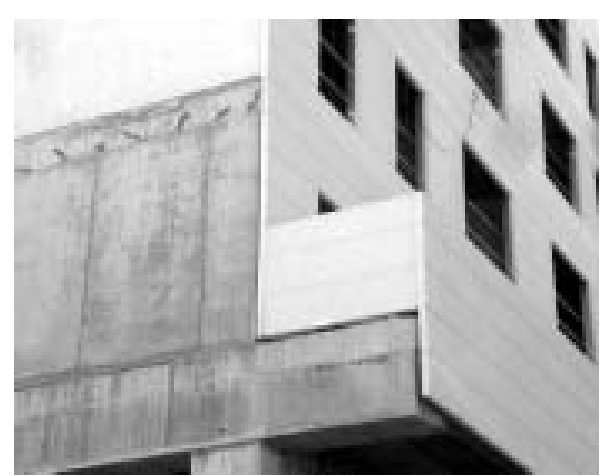

17. Detalle del peo que corona el pórtico de planta baja. Fachada este.

18. Vista de la esquina sur-este del edificio.

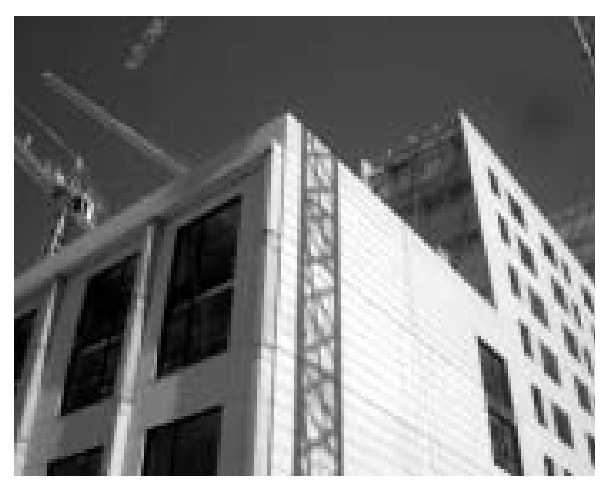

No existe una única zona de acopio de estos paneles en obra ya que se van suministrando desde fábrica, según los tiempos previstos por el planning y las necesidades de obra. Los paneles se descargan del camión a unos caballetes con peines en el espacio más cercano a su posición final, después, en caso de que las condiciones climáticas sean las convenientes, el operario de la grúa desliza el panel paralelo a fachada para que desde el interior sea colocado por los operarios de la obra.

Para completar la seguridad, los paneles cuentan con sistema anticaídas de fábrica, incorporado en los huecos de carpinterías. En los forjados se dejan las convenientes esperas para las barandillas de seguridad que se colocan en todos los perímetros de vuelo para ser usados a conveniencia.

El empleo de sistemas de fachadas de hojas pasantes permite reducir puentes térmicos de modo sencillo: eliminando los que tradicionalmente se producen en el apoyo de la hoja exterior en el canto de los forjados.

Además de los paneles $\mathrm{H}+\mathrm{A}$ como hoja exterior, ésta se recubre de $5 \mathrm{~cm}$ de poliuretano proyectado. Tras una separación de $64 \mathrm{~mm}$ se realiza la hoja interior a base de trasdosado de doble placa de yeso laminado, con perfilería de acero galvanizado. El conjunto multicapa en este caso alcanza un espesor total de $22 \mathrm{~cm}$. 

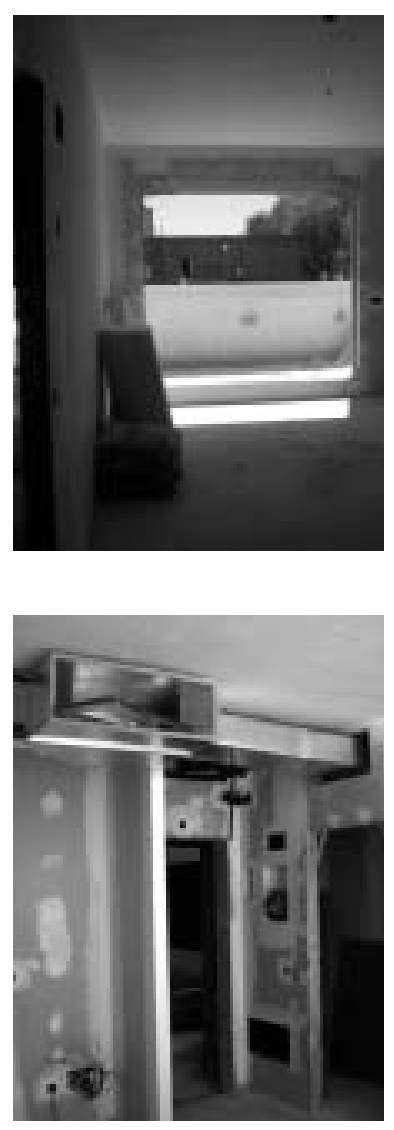

19

\section{OTROS ASPECTOS}

\subsection{Tabiquería}

Según los criterios ya dados por el Club de Roma, a finales de los 70, se rechazó, en vivienda, el contacto directo del usuario con el hormigón. El hormigón es un material que se pudiera decir hostil para la habitabilidad del usuario por su mal comportamiento frente al equilibrio higrotérmico interior y sus dificultades para la fijación de elementos decorativos u otras necesidades del usuario.

Por ello, desde que se pusieron en el mercado las placas de yeso laminado, se han convertido en un revestimiento ideal de estos paramentos de hormigón para suplir esas dificultades.

Así, el yeso es, en cambio, un material con muy buen comportamiento higrotérmico dentro de la vivienda, pues cede humedad cuando el usuario lo necesita y absorbe en caso contrario. Tampoco representa ningún obstáculo para la fijación de objetos en sus paramentos.

Asimismo, al estar industrializado en gran parte su montaje representa una buena solución que complementa la de los paneles prefabricados de hormigón.

En este edificio, se ha realizado, en gran parte, una tabiquería seca a base de paneles de placa de yeso laminado, con las que se realizan las divisiones dentro de una misma vivienda.

La división entre distintas viviendas, se hace trasdosando el muro prefabricado de hormigón armado que cumple con su papel estructural, trasdosándolo mediante rastreles tipo omega y placa de yeso laminado.

Por otro lado, las divisiones entre despachos profesionales, y las divisiones entre viviendas y zonas comunes, se ejecutan con fábrica de ladrillo de forma convencional, y trasdosado de placa de yeso laminado.

\subsection{Cubierta}

La cubierta es del tipo plana invertida multicapa, con láminas impermeabilizantes autoprotegidas, aislante térmico rígido y capacidad de tránsito para mantenimiento.

En cubierta se disponen de modo ordenado los cuartos de máquinas de ascensores, y el cuarto para instalaciones de telecomunicación. También se ubican los cuartos de calderas y equipos de acumulación de energía solar producidos por los colectores de fachada.
Además, se dispone en superficie de soportes de preinstalación para los equipos de aire acondicionado que, en el futuro, previsiblemente se instalen.

Las chimeneas se realizan con fábrica armada de ladrillo hueco doble, revestido con mortero monocapa y deflectores de chapa metálica.

El remate de coronación del edificio, está constituido por un peto de panel prefabricado de hormigón armado, cámara ventilada y hoja interior de ladrillo hueco simple enfoscado y pintado.

\section{FACTORES BIOCLIMÁTICOS Y SOSTENIBILIDAD}

En la actualidad, parece que los criterios de sostenibilidad se adquieren y justifican al cumplimentar los distintos apartados de la normativa, CTE-DB-AE, que son las exigencias actuales referentes al ahorro energético.

Éstas mejoran sustancialmente lo solicitado por anteriores normas, como el CT-79 (cuyo origen fue la crisis generada por la disminución de oferta de la OPEP). No obstante, no podemos calificar un edificio de sostenible o ecoeficiente sólo por cumplir una norma de obligado cumplimiento.

Es por esto que vamos a tratar de averiguar si el conjunto edificado va más allá de la norma, veamos si ha adoptado criterios sostenibles y/o ecoeficientes.

El edificio basa su estrategia climática en 2 claros apartados:

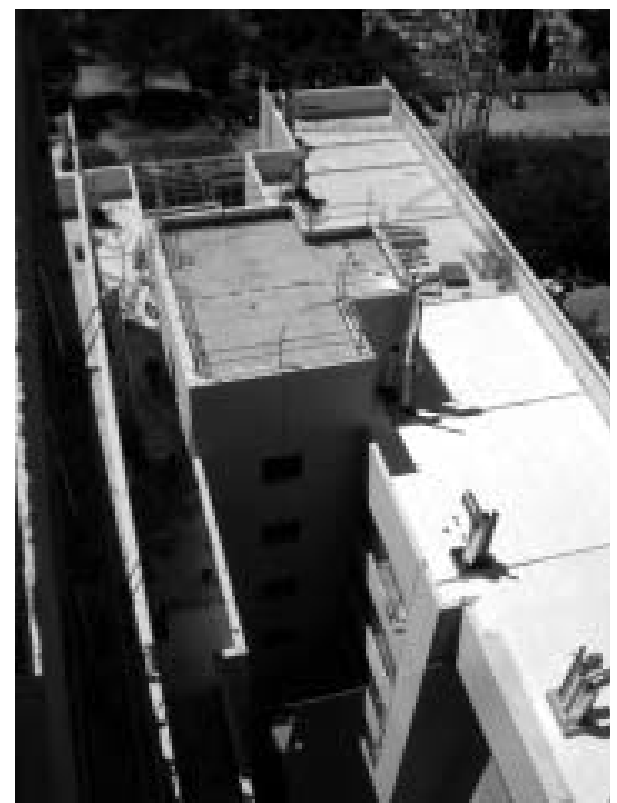


La inercia térmica producto de la masa interna del edificio como regulador de la energía recibida (tanto por radiación solar, como por aporte interno).

La inercia térmica, permite disponer de una mayor capacidad de almacenamiento de energía en el edificio, de modo que la regulación de la temperatura interna se produzca por suaves transiciones.

En el caso de los edificios realizados mediante sistemas de paneles prefabricados de hormigón, el aumento de la masa interna del edificio aumenta de modo proporcional la capacidad de almacenar energía (la cual depende, a su vez, de las características propias del material).

Si bien esta estrategia permite aprovechar de un modo óptimo la incidencia solar en la edificación, no reduce la pérdida de energía por la transmisión del flujo energético a través de los cerramientos. Esto se consigue por medio de las capas aislantes.

Actualmente en la zona Centro de España está muy generalizada la solución aislante, para los cerramientos opacos del conjunto, mediante la proyección de $5 \mathrm{~cm}$ de poliuretano proyectado. El poliuretano proyectado se produce por la reacción (exotérmica) de 2 componentes en estado líquido (poliol e isocianato MDI en proporción aproximada 1:1) los cuales espuman debido a la evaporación del propelente del poliol e incluso de algunas moléculas de agua que al reaccionar en la mezcla forman $\mathrm{CO}_{2}$.

Si bien el transporte del material se realiza de modo compacto, su aplicación en obra produce gases perjudiciales para el ser humano y el entorno, mientras se aplica, por lo que hay que adoptar precauciones especiales durante ese proceso. En la actualidad existe la tendencia al uso de otro tipo de aislantes más inertes, como son las mantas de fibra de roca o de otras fibras, que tienen el inconveniente de posibles desplazamientos del material hacia abajo, densificándose en esa zona y perdiendo cualidades aislantes en las partes superiores del trasdosado.

La otra estrategia empleada consiste en la diferenciación de las fachadas según la orientación de éstas.

En este caso, las fachadas Este y Oeste son similares, y disponen de grandes ventanales, con un retranqueo aproximado de $10 \mathrm{~cm}$. que permiten introducir la mayor cantidad de soleamiento en el edificio.

En Madrid, conscientes de su soleamiento y climatología, estas orientaciones funcionan

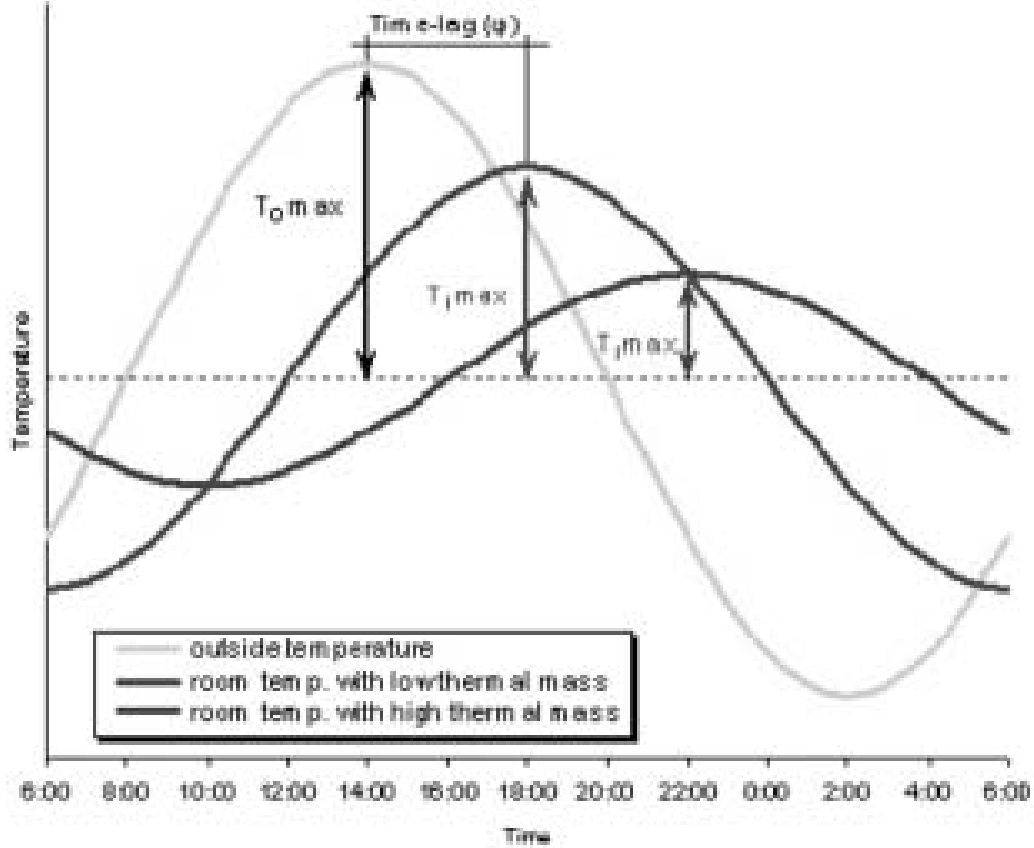

de modo óptimo si se dispone del suficiente retranqueo lateral para minimizar la exposición solar, debida a la apertura del arco de soleamiento en verano, es decir, minimizar la entrada de radiación horizontal Este, durante las horas de la mañana y, sobre todo, la de Poniente por la tarde.

Mientras, la fachada sur, predominantemente ciega, se emplea para la captación solar por medio de paneles, que se colocan por medio de una subestructura metálica ligera anclada a los paneles de hormigón, como se puede observar en la imagen.

La fachada norte dispone, a su vez, de muy reducida superficie acristalada, Con esto se reduce la transmitancia térmica global de la fachada. A pesar de ser ésta una receta muy eficaz de sostenibilidad ancestral, no debemos olvidar que se podrá ir reduciendo aún más la transmitancia térmica, según se vayan empezando a usar productos más innovadores, como: carpinterías de materiales transparentes (metacrilatos o policarbona-

21. Almacenamiento y transmisión de energía solar en $\mathrm{T}^{\circ}$ según la inercia térmica.

22. Detalle de la estructura metálica para el anclaje de los paneles solares.

23. La fachada sur del edificio con los paneles solares.

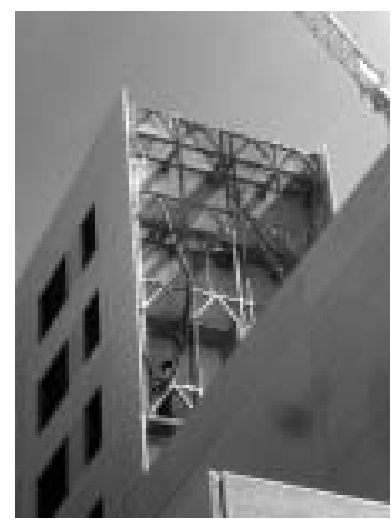

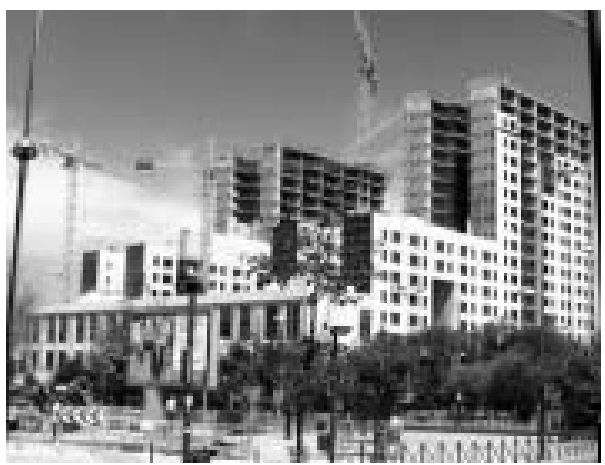




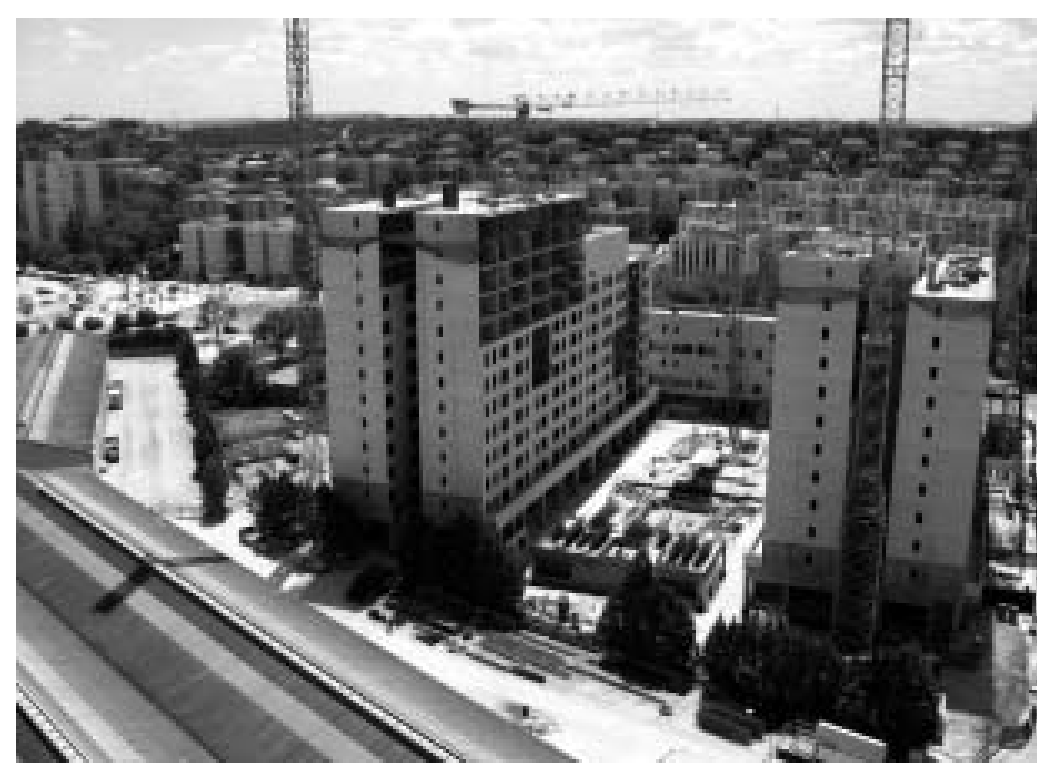

24. La fachada norte tos) o carpinterías de triple hoja, de doble ventana, o vidrios que reflejen aún más el espectro infrarrojo. También, se debe pensar en los beneficios producto de aumentar el espesor del aislamiento térmico en las partes opacas de fachada. De este modo, se hubiese podido mantener o disminuir la transmi- sión de energía aun disponiendo de mayor superficie acristalada.

\section{AGRADECIMIENTOS}

Para terminar, deseamos expresar nuestro agradecimiento a PRYCONSA y a CONSTRUCCIONES ORTIZ, por las facilidades que nos han concedido para realizar este trabajo, facilitándonos el acceso a las obras y a la documentación de la misma.

Especialmente, agradecemossu amable y eficaz ayuda a D. José Luis Cano, ICCyP, Director general Técnico de ORTIZ y uno de los mayores expertos en el tema de prefabricación y cálculo de paneles de hormigón, al Director de INDAGSA, el ingeniero D. Gonzalo de Córdoba, así como a los expertos del Departamento de Estructuras de INDAGSA, los ingenieros Sres. Cano Muñoz y Giménez de la Rosa, por la amabilidad, conocimientos y paciencia que han tenido en atendernos. Una vez más ha demostrado INDAGSA su apoyo a las peticiones de ayuda que le hacemos para facilitarnos la labor docente e investigadora, siendo un ejemplo de colaboración Universidad- Empresa, que se está demandando en esta sociedad del conocimiento.

\section{BIBLIOGRAFIA}

(1) B. Lewicki, "Edificación de viviendas prefabricadas con elementos de grandes dimensiones". Ed. IETCC. 1968.

(2) R. von Halász y G. Tantow. "La construcción con grandes elementos prefabricados". Ed. Urmo, 1972.

(3) A. del Águila, "Las tecnologías de la industrialización de los edificos de viviendas". 2 tomos. Ed. COAM 1987.

(4) A. del Águila, "La industrialización en la edificación de viviendas". Tomo 1: los Sistemas. Ed. Mairea 2006 (3).

(5) Ache, "Recomendaciones para el proyecto, ejecución y montaje de elementos prefabricados". Ed. Colegio ICCP 2004.

(6) A.J. Morris, "El hormigón premoldeado en la arquitectura". Ed. G. Gili. 1978.

(7) ATEP, "Estructuras de la edificación prefabricadas". 1996.

(8) C.I.B, "Recommandations internacionales pour les Structures en Panneaux". Ed. As. Italiana del Cemento. Roma.

(9) M. y P. Anderson, "Prefab prototypes: site-specific design for offsite construction". Ed. Princeton Architectural Press. New York, 2007.

(10) "Contemporary prefab houses". Ed. Daab GMBH, 2007.

(11) CATED, "Joints". Ed. du Moniteur. París, 1982. 